\title{
Utilización de los donantes añosos en pacientes trasplantados por cirrosis por virus $\mathbf{C}$
}

\author{
V. Aguilera, M. Ponce, M. Berenguer, R. Moreno' , J. M. Rayón², F. Sanjuán , M. Prieto y J. Mir \\ Servicio de Medicina Digestiva. Hospital La Fe. Ciberehd. 'Servicio de Gastroenterología. Hospital de Especialidades \\ LMN SXXI del IMSS. México D.F. ${ }^{2}$ Servicios de Anatomía Patológica y ${ }^{3}$ Cirugía, Unidad Hepática. Hospital La Fe. Valencia
}

\section{RESUMEN}

Introducción: la historia natural de la hepatitis $\mathrm{C}$ recurrente tras el trasplante hepático $(\mathrm{TH})$ es muy heterogénea, existiendo un porcentaje no despreciable de pacientes con evolución desfavorable. La identificación de factores asociados con peor evolución puede ayudar a mejorar el pronóstico de estos pacientes. La edad del donante se perfila como uno de los factores más importantes, pero es una variable difícilmente modificable.

Objetivos: a) describir la historia natural de los receptores $\mathrm{VHC}(+)$ en función de la edad del donante $(<0 \geq 50$ años) incluyendo la evolución clínica, analítica e histológica; b) identificar en el grupo de receptores de donantes $\geq 50$ años, aquellos factores precoces asociados con una evolución agresiva.

Métodos: estudio descriptivo y retrospectivo de la evolución clínica e histológica mediante biopsias de protocolo, de 162 trasplantados VHC (+) entre 1997-2001 con tiempo de seguimiento post-trasplante de al menos 12 meses. La hepatitis $\mathrm{C}$ relevante del injerto se definió por la progresión a fibrosis mayor a 1 durante el primer año, desarrollo de hepatitis colestásica fibrosante y/o pérdida del injerto por enfermedad VHC recurrente en cualquier momento durante los primeros 5 años. Los factores analizados como posibles factores predictivos de hepatitis $\mathrm{C}$ relevante fueron: a) relacionados con el receptor: demográficos (edad, sexo), pre-trasplante (hepatocarcinoma, estadio de Child, alcohol, marcadores serológicos del VHB, tratamiento antiviral, estado nutricional, analítica); b) relacionados con el donante: demográficos (edad, sexo), causa de fallecimiento, grado de esteatosis definido como ausente o mínima vs. moderada-grave $>10 \%$; c) relacionados con la cirugía: tiempos isquemia fría y recalentamiento, duración intervención, número de concentrados de hematíes transfundidos; y d) relacionados con el post-trasplante: inmunosupresión, analítica en el post-TH precoz ( $<14$ días), hepatitis aguda post$\mathrm{TH}$, complicaciones quirúrgicas precoces (vasculares y/o biliares).

Resultados: los pacientes se dividieron en dos grupos según la edad del donante $(<50$ años = grupo $1, \mathrm{n}=83,51 \%$ y $\geq 50$ años $=$ grupo $2, \mathrm{n}=79,49 \%)$. La mediana de seguimiento fue de 5 años (rango: 3 meses-8,5 años). El desarrollo de enfermedad relevante fue significativamente mayor en el grupo de donante añoso (64 vs. 20,5\%, p < 0,0001). En este grupo, la inmunosupresión potente -triple/cuadruple terapia- $(p=0,04)$ y el desarrollo de hepatitis aguda post-TH $(p=0,03)$ fueron las únicas

Recibido: 11-04-07.

Aceptado: 20-07-07.

Correspondencia: Marina Berenguer. Servicio de Medicina Digestivo. Hospital La Fe. Avda. Campanar, 21. 46009 Valencia. Fax: 961973 118. e-mail: mbhaym@teleline.es

\begin{abstract}
Background: the natural history of recurrent hepatitis $\mathrm{C}$ after liver transplantation (LT) is extremely variable, with progression to allograft failure in a substantial proportion of patients. The identification of factors associated with this poorer outcome may improve results. While donor age has been identified as one of the most important factors, the actual options to modify this variable are limited.
\end{abstract}

Objectives: a) to describe the natural history of $\mathrm{HCV}(+)$ liver transplant recipients depending on donor age ( $<$ or $\geq 50$ years), including clinical, biochemical, and histological outcomes; and b) to identify in the subgroup of organ recipients from aged donors ( $\geq 50$ years) factors associated with an aggressive course.

Methods: a retrospective study of clinical and histological data including protocol liver biopsies for $162 \mathrm{HCV}(+)$ liver transplant patients between 1997 and 2001 with at least one year of followup. Aggressive recurrent hepatitis $\mathrm{C}$ was defined as a progression to fibrosis $>1$ during the first year post-LT, development of a cholestatic form of recurrent hepatitis $\mathrm{C}$, and /or graft failure due to HCV during the first five years post-LT. Factors analyzed as potentially associated with recurrent hepatitis $\mathrm{C}$ included: a) recipient-related: demographics (age, sex), pre-transplantation (hepatocellular carcinoma, Child-Pugh classification, history of alcohol, HBV serological markers, antiviral treatment, nutritional status, biochemical variables); b) donor-related: demographics (age, sex), cause of death, grade of steatosis defined as minimal vs. moderate-severe $>10 \%)$; c) surgery-related: cold preservation and rewarming time, duration of procedure, blood transfusion; and d) post-LT management-related: immunosuppression, liver enzymes in the first 14 days post-LT, acute hepatitis post-LT, surgical complications (vascular and/or biliary).

Results: patients were divided into two groups according to donor age group 1 ( $<50$ years), $n=83,51 \%$, and group $2(\geq 50$ years), $\mathrm{n}=79,49 \%$ ). Median follow-up was 5 years (range: 3 months- 8.5 years). Aggressive recurrent hepatitis $C$ occurred significantly more frequently in the older donor group (64 vs. $20.5 \%, p<0.0001)$. In this group, potent immunosuppression -triple and quadruple regimens- $(p=0.04)$ and acute hepatitis post-LT ( $p=0.03$ ) were the only variables associated with aggressive recurrence. Degree of donor steatosis was not associated with the prognosis of recurrent hepatitis $C$. 
variables asociadas con el desarrollo de hepatitis relevante. El grado de esteatosis del donante no se asoció con el pronóstico de la hepatitis $\mathrm{C}$ recurrente.

Conclusión: la utilización de donantes añosos es, en parte, responsable de la progresión acelerada de la hepatitis tras el trasplante hepático. En caso de donantes añosos, debe evitarse la sobre-inmunosupresión y valorar la posibilidad de administrar tratamiento antiviral en los pacientes con hepatitis aguda recurrente.

Palabras clave: Trasplante hepático. Virus hepatitis C. Donantes. Cirrosis hepática.
Conclusion: the use of aged donors is partly responsible for the accelerated progression of hepatitis C after LT. When old donors are used we should avoid over-immunosuppression, and probably evaluate antiviral therapy in those with acute recurrent hepatitis C.

Key words: Liver transplantation. Hepatitis C virus. Donors. Liver cirrhosis.

Aguilera V, Ponce M, Berenguer M, Moreno R, Rayón JM, Sanjuán F, Prieto M, Mir J. Utilización de los donantes añosos en pacientes trasplantados por cirrosis por virus C. Rev Esp Enferm Dig 2007; 99: 581-587.

\section{INTRODUCCIÓN}

La cirrosis hepática por virus de la hepatitis $\mathrm{C}$ es la indicación más frecuente de de trasplante hepático (1). En estos pacientes, la recurrencia de la infección viral es la norma (2), y se asocia en la mayoría con el desarrollo de hepatitis histológica $(3,4)$. La historia natural de esta hepatitis se caracteriza por una elevada variabilidad, existiendo pacientes que evolucionan a cirrosis en menos de un año frente a otros con histología prácticamente normal tras 10 años de seguimiento. El porcentaje de pacientes que progresa a cirrosis es variable según las series, oscilando entre 10 y $30 \%$ a los 3-5 años $(3,4)$. Utilizando el grado de progresión histológica post-trasplante, se ha estimado que la mediana de tiempo para alcanzar el estadio de cirrosis es de aproximadamente 9-12 años, lo que supone una velocidad de progresión significativamente más rápida que la calculada para la población inmunocompetente $(1,5)$. Esta agresividad de la hepatitis $C$ en este colectivo de pacientes inmunodeprimidos condiciona una menor supervivencia respecto a la observada en pacientes trasplantados por cirrosis de etiología distinta al VHC, con cifras en torno al 60-70\% a los 5 años frente al $80 \%$ en el grupo control $(1,3-8)$. Además, datos preliminares sugieren que la progresión histológica es más rápida en pacientes trasplantados en los últimos años, lo cual condiciona una mayor tasa de desarrollo de cirrosis en los primeros años post-trasplante (7). Se ha sugerido que los principales factores relacionados con esta peor evolución son la edad del donante, es decir, la utilización de donantes de edad cada vez mayor (denominados donantes añosos), así como la mayor potencia en los regímenes inmunosupresores incorporados en los últimos años. Otros posibles factores implicados en esta progresión acelerada hacia la cirrosis son la gravedad y precocidad de los hallazgos histológicos en las biopsias iniciales, la infección por citomegalovirus y el genotipo $(4,5)$.

En un intento de mejorar el pronóstico de estos pacientes se han propuesto alternativas tales como, seleccionar un tratamiento inmunosupresor de menor potencia evi- tando los cambios bruscos (evitar el uso de bolos de corticoides y/u OKT3, y la retirada brusca de corticoides) (9), administrar tratamiento profiláctico frente al CMV en este colectivo, y dirigir los donantes de menor edad a los pacientes infectados por el VHC. Así como las dos primeras propuestas son relativamente factibles en la práctica clínica, la utilización de los "mejores donantes" en este colectivo plantea dificultades, no solamente de tipo ético, sino también de aplicabilidad, dada su escasez. De hecho, en nuestro centro, el porcentaje de donantes menores de 50 años fue solamente $48 \%$ en los últimos dos años.

Con estos antecedentes, nos propusimos realizar un estudio cuyos objetivos principales fueron: a) describir la historia natural de los receptores de trasplante hepático infectados por VHC, que recibieron donantes $\geq 50$ años en comparación con aquellos que recibieron donantes $<50$ años, incluyendo la evolución clínica, analítica e histológica; y b) identificar en el grupo de donantes $\geq 50$ años, otros factores precoces asociados con una evolución agresiva.

\section{PACIENTES Y MÉTODOS}

\section{Pacientes}

Entre enero de 1997 y diciembre de 2001 se realizaron en nuestro centro 224 trasplantes hepáticos primarios en pacientes infectados por el VHC sin coinfección por el VHB.

Los criterios de inclusión para el estudio fueron trasplante primario de hígado, seguimiento post-trasplante mayor de 12 meses (salvo en pacientes con pérdida del injerto en menos de 12 meses debido a la recurrencia del VHC), y ausencia de patologías asociadas que pudieran dificultar la valoración histológica (infección de novo por el VHB, problemas biliares post-TH). La presencia de hepatocarcinoma (HCC) injertado, conocido o incidental, no supuso un motivo de exclusión y los criterios para 
aceptar la indicación de trasplante hepático entre estos pacientes son los descritos previamente (7). De los 224 pacientes inicialmente valorados, fueron válidos 162 , siendo excluidos los 62 restantes por infección VHB de novo $(n=2)$, problema biliar asociado $(n=5)$, éxitus en el primer año no relacionado con la hepatitis $C(n=43)$, y/o ausencia de biopsia de protocolo o dificultad de valoración histológica $(n=12)$. Nuestro centro sigue una política estricta de realización de biopsias hepáticas anuales de protocolo en receptores infectados por VHC que nos permite valorar con gran precisión la evolución, no solamente clínica, sino también histológica de estos pacientes. El tiempo de seguimiento post-trasplante hepático de todos los pacientes fue de al menos 12 meses (salvo en aquellos pacientes con recidiva precoz agresiva, tales como los que desarrollaron hepatitis colestásica fibrosante y que fallecieron a causa de esta patología) con una mediana de 5 años (rango 3 meses-8,5 años). Se daba por concluido el seguimiento del paciente cuando este fallecía, cuando se sometía a re-trasplante hepático (cualquiera que fuera la causa de este) o tras el periodo marcado como final del presente estudio, es decir, mayo de 2005.

\section{Evaluación histológica}

Se realizaron biopsias hepáticas de protocolo a intervalos anuales. Estas biopsias se ampliaron en número y/o se adelantaron en el tiempo cuando se consideraron indicadas, según la evolución clínico-analítica.

Todas las biopsias fueron analizadas por un mismo anatomo-patólogo y fueron tratadas con las tinciones rutinarias. Las biopsias catalogadas como hepatitis fueron clasificadas usando tanto el estadio de fibrosis como el grado de actividad necroinflamatoria, tal como se ha publicado previamente $(6,10)$. De forma resumida, la actividad histológica se calculó a partir de la necrosis periportal, necrosis y degeneración lobular e inflamación portal, de tal forma que la puntuación de 1 a 2 se definieron como mínima; de 3 a 6 como leve; de 7 a 10 como moderada; y de 11 a 14 como grave. El estadio de fibrosis fue de 0 si estaba ausente, 1 en caso de expansión fibrosa portal; 3 en caso de puentes de fibrosis y 4 si cirrosis.

Se definió hepatitis relevante del injerto ante la progresión a fibrosis mayor a 1 durante el primer año, el desarrollo de hepatitis colestásica fibrosante y/o la pérdida del injerto por enfermedad VHC recurrente en los primeros 5 años. Se optó por este nivel de umbral de fibrosis ya que en diversos estudios, la presencia de fibrosis $\geq 1$ en la primera biopsia anual se ha asociado con progresión posterior agresiva.

Se realizaron de manera rutinaria biopsias hepáticas pre- y post- reperfusión del injerto con el objetivo de evaluar en cada caso su calidad y se valoró el grado de esteatosis según la siguiente puntuación: 1 o mínima: $<10 \%$ de los hepatocitos con esteatosis, 2 o leve: 11-20\%, 3 o moderada: $>21-30 \%, 4$ o grave: esteatosis $>30 \%$.

\section{Inmunosupresión}

La terapia de inmunosupresión de inducción fue muy variable según el ensayo en el que se incluyó al paciente, y la función renal/cerebral del paciente en el momento del trasplante y/o postoperatorio inmediato; y consistió en: a) doble terapia con tacrolimus + esteroides $(n=75)$; b) doble terapia con ciclosporina + esteroides $(n=19)$; $)$ triple terapia con tacrolimus, micofenolato mofetil y daclizumab $(\mathrm{n}=3)$; d) triple terapia con ciclosporina, esteroides y basiliximab/daclizumab $(\mathrm{n}=13)$; e) doble terapia con tacrolimus y daclizumab $(n=4)$; f) tacrolimus + sirolimus + esteroides $(\mathrm{n}=1) ; \mathrm{g})$ triple terapia con tacrolimus, esteroides y basiliximab/daclizumab $(n=4)$; h) ciclosporina + azatioprina + esteroides $(n=31) ; \mathrm{i})$ atgam + ciclosporina o tacrolimus + esteroides $(n=3)$; j) tacrolimus + azatioprina + esteroides $(\mathrm{n}=7)$; y k) cuádruple terapia con atgam, esteroides, ciclosporina y azatioprina $(n=2)$. Las dosis iniciales de los inmunosupresores fueron: a) corticosteroides: metilprednisona por vía intravenosa y a dosis progresivamente descendentes empezando el día 1 post-trasplante con $200 \mathrm{mg}$ hasta alcanzar $20 \mathrm{mg}$ de prednisona por vía oral a partir del día 7. La pauta posterior ha sido variable, y mientras que en algunos casos, la retirada fue progresiva manteniendo dicho fármaco hasta el año post-trasplante, en otros, se siguió un protocolo de retirada rápida de este tratamiento (retirada en los primeros 6 meses, $\mathrm{n}=26$ ); b) ciclosporina: se administró la dosis necesaria para mantener niveles sanguíneos entre 250-350 ng/ml durante el primer mes; $150-250 \mathrm{ng} / \mathrm{ml} \mathrm{du}-$ rante el segundo y el tercer mes; $100-150 \mathrm{ng} / \mathrm{ml}$ a partir del cuarto mes y hasta finalizar el primer año; y en torno a 50-100 ng/ml trascurrido el primer año del trasplante; c) tacrolimus: se administró la dosis necesaria para mantener niveles sanguíneos comprendidos entre 5-15 ng/ml durante los primeros 3 meses y posteriormente entre $5-10 \mathrm{ng} / \mathrm{ml}$; d) micofenolato mofetil: se administró a la dosis de $1 \mathrm{~g} / 12 \mathrm{~h}$ vía oral; e) sirolimus: se administró la dosis necesaria para mantener niveles en sangre entre 4-11 ng/ml; f) basiliximab: $20 \mathrm{mg}$ vía intravenosa el día del trasplante y el $4^{\circ}$ día post-trasplante; y g) daclizumab: $2 \mathrm{mg} / \mathrm{kg}$ tras hepatectomía y luego $1 \mathrm{mg} / \mathrm{kg}$ entre el $7^{\circ}$ y $20^{\circ}$ día.

La pauta de inmunosupresión a largo plazo se ha ido modificando a lo largo del tiempo. Así, los inmunosupresores considerados de segunda línea, tales como micofenolato mofetil y esteroides, se han ido retirando progresivamente antes, en general durante los primeros 6 meses post-trasplante.

Las decisiones en relación a los cambios en el tipo de inmunosupresión en función de la evolución del injerto no han sido establecidas de manera uniforme con lo que su análisis no es posible en este estudio. Aunque cabe señalar, a modo informativo, que se ha observado una tendencia a evitar el exceso de inmunosupresión entre los pacientes que desarrollaron hepatitis $C$ recurrente en el injerto, mediante la disminución de las dosis de fármacos tales como ciclosporina, tacrolimus y corticoides. 
Se definió inmunosupresión potente cuando el paciente recibió triple y/o cuádruple terapia a dosis máximas.

\section{Profilaxis de la infección por citomegalovirus}

Se administró tratamiento antiviral con ganciclovir 1421 días cuando se pautaba por vía intravenosa o valganciclovir durante 90 días cuando la administración era por vía oral, en las siguientes circunstancias: a) donante positivo y receptor negativo en los resultados de la serología estándar para detección de citomegalovirus; b) a todos los pacientes sometidos a re-trasplante hepático; c) en los casos de utilización de anticuerpos mono o policlonales; y d) en situaciones en los que fue necesaria la politransfusión.

\section{Factores predictivos de enfermedad relevante por VHC y/o con la supervivencia del paciente y/o del injerto}

Con el fin de establecer una evolución diferente en función de la edad del donante se dividió a los pacientes en dos grandes grupos: por un lado, aquellos receptores que recibieron el órgano de donantes menores de 50 años (grupo 1) y, por otro, aquellos que lo recibieron de donantes de edad mayor o igual a 50 años (grupo 2). Se analizaron variables del receptor, donante, cirugía, inmunosupresión y del post-trasplante precoz como posibles variables predictivas del desarrollo precoz de enfermedad grave del injerto (Tabla I).

En un subgrupo de pacientes (los más recientes 19992001) se analizaron otras variables para conocer la implicación, no sólo clínica, sino económica derivada de la utilización de donantes añosos, tales como: causas de fallecimiento, la necesidad de reingresos hospitalarios, la duración de los mismos, días en reanimación y número de reingresos.

El genotipo no fue considerado con un factor predictivo potencial, ya que la inmensa mayoría de los pacientes trasplantados en nuestro centro infectados por el VHC genotipo $1 \mathrm{~b}$. La carga viral no pudo ser evaluada al no existir muestras en todos, y haber variado las técnicas virológicas a lo largo del tiempo.

\section{Retrasplante}

No se consideró la posibilidad de re-trasplante si el paciente había desarrollado cirrosis del injerto durante el primer año tras el trasplante, ni en aquellos mayores de 65 años.

\section{Análisis estadístico}

Los pacientes se dividieron en dos grupos según la edad del donante $(<50, \geq 50$ años). Las variables categóricas se compararon mediante el test $\chi^{2}$ o test exacto de Fisher's cuando estuviese indicado. En caso de variables categóricas ordenadas, las comparaciones se realizaron mediante el $\chi^{2}$ de tendencias. Las variables continuas se expresan como medias $\pm \mathrm{DE}$ comparándose mediante el test $\mathrm{t}$ de Student. Si estas variables no se ajustaban a la normalidad, se expresaron mediante la mediana y el rango, comparándose con el test Mann-Whitney. Se consideró como estadísticamente significativo un valor de $\mathrm{p} \leq 0,05$. Todos los análisis estadísticos fueron realizados con el SPSS 9.0 (SPSS Inc., Chicago, IL).

\section{RESULTADOS}

\section{Características de los dos grupos de pacientes por edad del donante}

La mitad de los pacientes $(83 / 162,51 \%)$ recibieron el órgano procedente de un donante de edad menor a 50 años (grupo 1) mientras que el resto $(\mathrm{n}=79,49 \%)$ de uno

Tabla I. Factores analizados potencialmente predictivos de enfermedad relevante por VHC

\begin{tabular}{|c|c|c|c|c|c|c|}
\hline Receptor & Donante & Cirugía & Reanimación & IS & Analitica post-TH & Otras \\
\hline 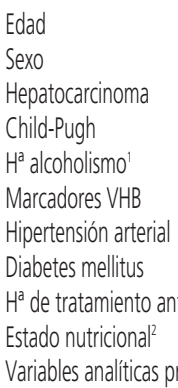 & $\begin{array}{l}\text { Edad } \\
\text { Sexo } \\
\text { Causa éxitus } \\
\text { Esteatosis }^{3} \\
\text { iral pre-TH } \\
\text { TH }\end{array}$ & $\begin{array}{l}\text { Tiempo isquemia fría } \\
\text { Tiempo isquemia caliente } \\
\text { Tiempo isquemia total } \\
\text { Duración intervención } \\
\mathrm{N}^{0} \text { concentrados de hematies }\end{array}$ & $\begin{array}{l}\text { Duración en días } \\
\text { Uso de PG }\end{array}$ & $\begin{array}{l}\text { Inducción } \\
\text { Cambio IS } \\
\text { Rechazo } \\
\text { Tratamiento rechazo }\end{array}$ & $\begin{array}{l}\text { Glucemia } \\
\text { Creatinina } \\
\text { Bilirrubina } \\
\text { Aspartato y alanina aminotransferasa } \\
\text { Gammaglutamil transpeptidasa } \\
\text { Colesterol } \\
\text { Plaquetas } \\
\text { Leucocitos }\end{array}$ & $\begin{array}{l}H^{\text {a }} \text { hepatitis C recurrente aguda } \\
\text { Complicaciones quirúrgicas precoces vasculares } \\
\text { Complicaciones quirúrgicas precoces biliares } \\
\text { IMC }^{4} \\
\text { Dosis corticoides } \\
\text { Niveles inhibidores calcineurina }{ }^{4}\end{array}$ \\
\hline
\end{tabular}


mayor o igual a 50 años (grupo 2). Las características de estos dos grupos se resumen en la tabla II. Ambos grupos fueron similares en la mayoría de las variables a excepción del IMC del donante y la presencia de esteatosis, tal como cabía esperar (11).

Tabla II. Caraterísticas basales de los pacientes según la edad del donante

\begin{tabular}{|c|c|c|c|}
\hline & $\begin{array}{c}\text { Grupo 1: } \\
\text { Donantes < } 50 \\
\text { años }(n=83)\end{array}$ & $\begin{array}{c}\text { Grupo 2: } \\
\text { Donantes } \geq 50 \\
\text { años }(n=79)\end{array}$ & $p$ \\
\hline $\begin{array}{l}\text { Edad donante en años } \\
\text { (mediana, rango) }\end{array}$ & $31(13-49)$ & $62(50-84)$ & 0,0001 \\
\hline $\begin{array}{l}\text { Sexo donante } \\
\text { (\% varón) }\end{array}$ & $55(66 \%)$ & $45(57 \%)$ & 0,2 \\
\hline IMC donante $\left(\mathrm{kg} / \mathrm{m}^{2}\right)$ & $24,5(18-34)$ & $26(21-71)$ & 0,001 \\
\hline Esteatosis donante (\% sí) & $12(14,5 \%)$ & $21(27 \%)$ & 0,05 \\
\hline $\begin{array}{l}\text { Esteatosis donante } \\
\text { relevante }(>10 \%)\end{array}$ & $5(6 \%)$ & $10(13 \%)$ & 0,1 \\
\hline Edad receptor en años & $58(34-67)$ & $55(33-68)$ & 0,08 \\
\hline $\begin{array}{l}\text { Sexo receptor } \\
\text { (\% varón) }\end{array}$ & $49(59 \%)$ & $54(68 \%)$ & 0,2 \\
\hline $\begin{array}{l}\text { Historia de consumo de } \\
\text { alcohol (\%) }\end{array}$ & $13(16 \%)$ & $20(25 \%)$ & 0,1 \\
\hline $\mathrm{CHC}$ & $31(37 \%)$ & $32(40,5 \%)$ & 0,7 \\
\hline Child C (\%) & $23(28 \%)$ & $29(37 \%)$ & 0,5 \\
\hline \multicolumn{4}{|l|}{ Estado nutricional } \\
\hline Regular-malo (\%) & $26(33 \%)$ & $25(34 \%)$ & 0,9 \\
\hline $\begin{array}{l}\text { Tiempo de isquemia total } \\
\text { en min (mediana, rango) }\end{array}$ & $330(155-735)$ & $370(140-825)$ & 0,09 \\
\hline Transfusión sangre (U) & $2(0-14)$ & $3(0-8)$ & 0,7 \\
\hline IS inicial con ciclosporina & $34(41 \%)$ & $36(46 \%)$ & 0,5 \\
\hline IS inicial con azatioprina & $20(24 \%)$ & $20(25 \%)$ & 0,8 \\
\hline Bolos de MP (\%) & $9(11 \%)$ & $5(6 \%)$ & 0,4 \\
\hline Duración prednisona (días) & $318(31-731)$ & $308(17-1415)$ & 0,3 \\
\hline
\end{tabular}

\section{Historia natural de la hepatitis $\mathrm{C}$ recurrente. Desarrollo de enfermedad relevante por virus $\mathrm{C}$}

La evolución histológica y desarrollo de enfermedad relevante fue significativamente mayor en el grupo de donante añoso frente al de menos de 50 años. Un 64\% de pacientes del grupo de donante años desarrolló una enfermedad relevante frente a solamente un $20,5 \%$ del grupo de donantes menores de 50 años. Sin llegar a ser estadísticamente significativo, otras complicaciones, tales como complicaciones quirúrgicas y disfunción primaria del injerto también fueron más frecuentes en el grupo añoso (Tabla III).

\section{Variables implicadas en la evolución histológica}

Las variables estadísticamente significativas $(\mathrm{p}<0,05)$ o cercanas a la asociación estadística $(\mathrm{p}<0,1)$ asociadas
Tabla III. Complicaciones post-trasplante y evolución clínica e histológica según edad del donante

\begin{tabular}{lccc}
\hline & $\begin{array}{c}\text { Grupo 1: } \\
\text { Donantes < 50 } \\
\text { años }(n=83)\end{array}$ & $\begin{array}{c}\text { Grupo 2: } \\
\text { Donantes } \geq 50 \\
\text { años }(n=79)\end{array}$ & $p$ \\
\hline DPI (\% disfunción) & $8(19,5 \%)$ & $15(30,6 \%)$ & 0,2 \\
Complicación quirúrgica & $13(16 \%)$ & $19(24 \%)$ & 0,2 \\
Hepatitis aguda & $20(24 \%)$ & $26(33 \%)$ & 0,2 \\
Rechazo & $22(26 \%)$ & $15(19 \%)$ & 0,2 \\
Tiempo hasta hepatitis (días) & $102(30-396)$ & $69(7-168)$ & 0,07 \\
Enfermedad relevante (fibrosis & $17(20,5 \%)$ & $50(64 \%)$ & 0,0001 \\
$>1$ en el 1'r año, HCF, CH en & & & \\
< 5 años) & & & \\
Fibrosis > 1 al año del TH & $33(43 \%)$ & $63(84 \%)$ & 0,0001 \\
Estado del paciente (\% éxitus) & $19(23 \%)$ & $33(42 \%)$ & 0,01 \\
\hline DPI: disfunción primaria del injerto; HCF: hepatitis colestásica fibrosante; CH: cirro- \\
sis hepática; TH: trasplante hepático.
\end{tabular}

con progresión a enfermedad relevante en ambos grupos y en los grupos 1 y 2 de forma separada se muestran en la tabla IV.

Tabla IV. Variables implicadas en la evolución histológica de la hepatitis C recurrente

\begin{tabular}{lll}
\hline $\begin{array}{l}\text { Análisis con todos } \\
\text { los pacientes }\end{array}$ & $\begin{array}{c}\text { Análisis en el grupo } \\
1(<\text { de } 50 \text { años })\end{array}$ & $\begin{array}{l}\text { Análisis en el grupo } \\
2(\geq 50 \text { años })\end{array}$ \\
\hline Edad del donante & Ausencia de alcohol significativo & \\
$\begin{array}{l}(p<0,0001) \\
\text { Complicaciones quirúrgicas }\end{array}$ & $\begin{array}{c}\text { Ede-trasplante }(p=0,06) \\
\text { Edad del receptor }(p=0,046)\end{array}$
\end{tabular}

Complicaciones quirúrgicas Edad del receptor $(p=0,046)$

$(p=0,004)$

Desarrollo de hepatitis aguda Desarrollo de hepatitis aguda Desarrollo de hepatitis aguda post-TH $(p=0,0001) \quad$ post-TH $(p=0,02) \quad$ post- $T H(p=0,03)$

Tiempo hasta hepatitis Tiempo hasta hepatitis $(p=0,003) \quad(p=0,002)$

Duración de prednisona tiempo de isquemia caliente Duración de prednisona

$(p=0,02)$ $(p=0,05)$

$(p=0,068)$

Inmunosupresión potente

Inmunosupresión potente triple/cuádruple terapia$(p=0,028)$

$(p=0,001)$

Nivel de AST al $11^{\text {er }}$ mes del

TH $(p=0,002)$

Nivel de ALT al $1^{\text {er }}$ mes del

$\mathrm{TH}(\mathrm{p}=0,008)$

Nivel de GGT al 1 1er mes del

$\mathrm{TH}(\mathrm{p}=0,006)$

Nivel de fosfatasas alcalinas

$1^{\text {er }}$ mes del $\mathrm{TH}(\mathrm{p}=0,004)$

TH: trasplante hepático; ALT: alanino aminotransferasa; AST: aspartato aminotransferasa; GGT: gamma glutamil transpeptidasa.

\section{Implicaciones sobre el coste económico}

Tanto el número de reingresos como la duración inicial en reanimación fueron significativamente mayores en los pacientes del grupo añoso que en el joven (Tabla V). Los tratamientos utilizados tales como inmunosupresión y el consumo de hemoderivados, por el contrario, fue similar en ambos grupos (Tabla II). 
Tabla V. Estancia hospitalaria según edad del donante

\begin{tabular}{|c|c|c|c|}
\hline & $\begin{array}{c}\text { Grupo 1: } \\
\text { Donantes < } 50 \\
\text { años }(n=83)\end{array}$ & $\begin{array}{c}\text { Grupo 2: } \\
\text { Donantes } \geq 50 \\
\text { años }(n=79)\end{array}$ & $p$ \\
\hline Días en reanimación & $2(1-31)$ & $3(1-15)$ & 0,03 \\
\hline $\begin{array}{l}\text { Tiempo hospitalización } \\
\text { inicial en días }\end{array}$ & $17(1-137)$ & $17(2-210)$ & 0,9 \\
\hline $\mathrm{N}^{\circ}$ reingresos & $1(0-6)$ & $1(0-6)$ & 0,015 \\
\hline
\end{tabular}

\section{DISCUSIÓN}

La hepatitis $\mathrm{C}$ post-trasplante se ha convertido en un problema de primer orden en la mayoría de los centros de trasplante debido a su elevada morbilidad y mortalidad. Una de las variables implicadas en la progresión acelerada de la hepatitis es la utilización de órganos marginales, tales como aquellos que provienen de donantes añosos $(1,3,12)$. En este estudio se confirma este hallazgo, similar a lo observado en el paciente inmunocompetente, donde la edad en el momento de la infección destaca como factor de mal pronóstico (13).

Aunque la indicación de trasplante para los pacientes afectos de cirrosis por VHC sigue estando bien establecida, la mortalidad elevada en este colectivo obliga a encontrar soluciones para mejorar su pronóstico. La solución ideal sería trasplantar a estos pacientes con viremia negativa; desafortunadamente, $y$ al contrario de la hepatitis $\mathrm{B}$, no se dispone en la actualidad de fármacos antivirales potentes y bien tolerados que puedan administrarse a pacientes con enfermedad hepática por VHC avanzada. Teniendo en cuenta la asociación entre la edad del donante y la peor evolución histológica, una alternativa sería la de dirigir órganos menos añosos a los receptores infectados por el VHC. Esta alternativa, no obstante, plantea dificultades no sólo de tipo ético sino de aplicabilidad. En efecto, en los últimos años se ha apreciado un cambio en el perfil de los donantes, habiendo disminuido aquellos por muerte accidental y aumentado los secundarios a accidentes cerebro-vasculares $(3,12)$. Estos cambios han condicionado un incremento en la edad del donante de aproximadamente 10 años en el última década, situación que posiblemente se mantenga en los próximos años $(3,12)$.

Existen diversas teorías que intentan explicar las razones del envejecimiento hepático. La alteración progresiva de los mensajes genéticos, el estrés oxidativo mitocondrial, la pérdida de telómeros y alteración de la respuesta inmunitaria son algunas de las teorías existentes (14-16). Además, los hígados de personas mayores sufren alteraciones macroscópicas, tales como la disminución del tamaño y la adquisición de un aspecto más oscuro y a nivel microscópico, se aprecia un mayor acúmulo de lipofucsina, más esteatosis, más sobrecarga férrica y mayores grados de fi- brosis e inflamación sin aparente causa desencadenante (14-16). Todos estos cambios asociados a la persistencia de la hepatitis $\mathrm{C}$ probablemente condicionen una evolución más agresiva en el paciente trasplantado $(17,18)$.

Una segunda alternativa a la hora de mejorar el pronóstico de estos pacientes es definir en aquellos que reciben órganos de donantes añosos, los factores asociados con mala evolución, fundamentalmente aquellos presentes antes del trasplante y/o que se desarrollen en el posttrasplante precoz. Con estos datos se podría intentar un tratamiento antiviral precoz en los pacientes que cumpliesen las condiciones de mala evolución. Este fue el objetivo principal de nuestro estudio, cuyas conclusiones más importantes se detallan a continuación. En el grupo de donantes añosos, el desarrollo de hepatitis aguda en los primeros meses post-trasplante junto a una mayor utilización de triple y cuádruple terapias inmunosupresoras y un menor tiempo de prednisona se asociaron a una peor evolución histológica post-trasplante. Estos datos confirman los hallazgos de estudios anteriores tanto de nuestro grupo como de otros $(9,19)$, y sugieren que una mejor utilización de la inmunoupresión evitando estados de sobreinmunosupresión junto a cambios bruscos en los inmunosupresores utilizados sea la clave para mejorar el pronóstico, tal como hemos descrito recientemente en un estudio prospectivo (9).

Es interesante destacar cómo la presencia de esteatosis no parece desempeñar un papel a la hora de determinar el curso de la hepatitis $\mathrm{C}$ recurrente, ni en el grupo de donantes jóvenes ni en los añosos. Este hallazgo es importante ya que hoy en día, la prevalencia de esteatosis mayor de $30 \%$ en la población general es del $10 \%$ (11). Si bien en estudios previos se ha observado que la presencia de esteatosis moderada-grave $(>30 \%)$ se asocia a una menor supervivencia al año, a una pobre respuesta inicial del injerto y a una mayor incidencia de fallo primario del injerto $(17,20,21)$, nosotros optamos por definir "esteatosis relevante" aquella superior al $10 \%$ porque el número de biopsias del donante con esteatosis mayor al $30 \%$ era prácticamente inexistente $(\mathrm{n}=3)$. El mecanismo a través del cual la esteatosis del donante condiciona problemas en el post-trasplante no está aclarado, pero es posible que se deba a la mayor susceptibilidad al daño secundario a isquemia-reperfusión. El empeoramiento del pronóstico observado con hígados esteatósicos es independiente de la indicación del trasplante y se refiere fundamentalmente a la supervivencia a corto plazo $(17,20,21)$. Se ha especulado que al igual que sucede en el individuo inmunocompetente, la esteatosis del donante también condicionaría un peor pronóstico a largo plazo al favorecer la progresión de la hepatitis C. En nuestro estudio, sin embargo, y centrándonos sobre todo en el grupo de donantes añosos, la esteatosis parece perder importancia a la hora de predecir una mala evolución. Es posible que en este grupo, la existencia de numerosas alteraciones asociadas con el envejecimiento, tengan suficiente peso para condicionar una mala evolución, independientemente del grado de estea- 
tosis. Es posible no obstante que en nuestra serie la escasez en el número de donantes con esteatosis moderada (entre 20 y $30 \% ; n=4$ ) o severa (mayor del 30\%; $n=3$ ) sea la responsable de la ausencia de asociación.

En conclusión, la utilización de donantes añosos condiciona una peor evolución histológica de la hepatitis $\mathrm{C}$ post-trasplante, la cual a su vez se asocia con un mayor gasto socio-sanitario secundario al número elevado de reingresos y estancias prolongadas. Si se utilizan donantes añosos, y teniendo en cuenta que la eficacia del tratamiento antiviral en pacientes trasplantados ha mejorado en los últimos años (22), se podría iniciar un tratamiento antiviral de forma precoz, fundamentalmente en aquellos que desarrollan una elevación importante de transaminasas con desarrollo de hepatitis aguda en los primeros meses. Igualmente, es necesario evitar una sobre-inmunosupresión con utilización de triple o cuádruple terapia a dosis plenas en este tipo de pacientes.

\section{BIBLIOGRAFÍA}

1. Berenguer M, Lopez-Labrador FX, Wright TL. Hepatitis C and liver transplantation. J Hepatol 2001; 35: 666-78.

2. Garcia-retortillo M, Forns X, Feliu A, et al. Hepatitis C virus kinetics during and immediately after liver transplantation. Hepatol 2002; 35: 680-7.

3. Wiesner RH, Sorrell M, Villamil F. Report of the First International Liver Transplant Society Consensus Conference on Liver Transplantation and Hepatitis C. Liver Transpl 2003; 9 (Supl. 3): S1-S9.

4. Berenguer M. Hepatitis $\mathrm{C}$ after liver transplantation: Risk factors, outcomes, and treatment. Curr Op Organ Transpl 2005; 10 (2): 81-9.

5. Aguilera V, Berenguer M. Hepatitis C and fibrosis. Rev Esp Enferm Dig 2004; 96: 402-14.

6. Forman LM, Lewis JD, Berlin JA, et al. The association between hepatitis $\mathrm{C}$ infection and survival after orthotopic liver transplantation. Gastroenterology 2002; 122: 889-96.

7. Berenguer M, Prieto M, San Juan F, et al. Contribution of donor age to the recent decrease in patient survival among HCV-infected liver transplant recipients. Hepatology 2002; 36: 202-10.

8. Neumann UP, Berg T, Bahra M, et al. Long-term outcome of liver transplants for chronic hepatitis C: A 10-year follow-up. Transplantation 2004; 77: 226-31.

9. Berenguer M, Aguilera V, Prieto M, et al. Significant improvement in the outcome of $\mathrm{HCV}$-infected transplant recipients by avoiding rapid steroid tapering and potent induction immunosuppression. J Hepatol 2006; 44 (4): 717-22

10. Solis Herruzo JA. Current indications of liver biopsy. Rev Esp Enferm Dig 2006; 98: 122-39.

11. Hilden M, Christoffersen P, Juhl E, Dalgaard JB. Liver histology in a "normal" population-examination of 503 consecutive fatal traffic casualties. Scand J Gastroenterol 1997; 12: 593-7.

12. Samuel D, Forns X, Berenguer M, et al. Report of the Monothematic EASL Conference on Liver Transplantation for Viral Hepatitis (Paris, France, January 12-14, 2006). J Hepatol. 2006; 45 (1): 127-43.

13. Poynard T, Bedossa P, Opolon P for the OBSVIRC, CLINIVIRC and DOSVIRC groups. Natural history of liver fibrosis progression in patients with chronic hepatitis C. Lancet 1997; 349: 825-32.

14. Fromenty B, Mansouri A, Degoul F, Demeilliers C, Gaou I, Pessayre D. Ageing, alcohol and mitochondria. Gastroenterol Clin Biol 2000; 24: $349-58$

15. Oullette MM, Savre-Train I. Les télomères et le vieillisement des cellules. Médecine-Sciencies 2000; 16: 47-80

16. Hornboll P, Olsen TS. Fatty changes in the liver: the relation to age, overweigth and diabetes mellitus. Acta Pathol Microbiol Immunol Scand (A); 1982: 90: 199-205

17. Imber CJ, St Peter SD, Handa A, Friend PJ. Hepatic steatosis and its relationship to transplantation. Liver Transplant 2002; 5: 415-23.

18. Machicao VI, Bonatti H, Krishna M, Aqel BA, Lukens FJ, Nguyen $\mathrm{JH}$, et al. Donor age affects fibrosis progression and graft survival after liver transplantation for hepatitis C. Transplantation 2004; 77: 84-92.

19. Samonakis DN, Triantos CK, Thalheimer U, et al. Immunosuppression and donor age with respect to severity of HCV recurrence after liver transplantation. Liver Transpl 2005; 11 (4): 384-5.

20. Verran D, Taras K, Painter D, Fisher J, Koorey D, Strasser S, et al. Clinical experience gained from the use of 120 steatosic donor livers for orthotopic liver transplantation. Liver Transpl 2003; 5: 500-5.

21. Trevissani F, Colantoni A, Carareni P, Van Thiel DH. The use of donor fatty liver for liver transplantation: A challenge or a quagmire? J Hepatol 1996; 24: 114-21.

22. Berenguer M, Palau A, Fernandez A, Benlloch S, Aguilera V, Prieto $\mathrm{M}$, et al. Efficacy, predictors of response, and potential risks associated with antiviral therapy in liver transplant recipients with recurrent hepatitis C. Liver Transpl 2006; 12: 1067-76. 